Yayın Geliş Tarihi: 25.09.2020

Yayına Kabul Tarihi: 19.07.2021

Online Yayın Tarihi: 30.09.2021

http://dx.doi.org/10.16953/deusosbil.800077
Dokuz Eylül Üniversitesi

Sosyal Bilimler Enstitüsü Dergisi

Cilt: 23, Sayı: 3, Y1l: 2021, Sayfa: 1179-1192

ISSN: 1302-3284 E-ISSN: 1308-0911

Araştırma Makalesi

\title{
ILLERIN PATENT SAYISINI ETKİLEYEN FAKTÖRLER ÜZERİNE BİR UYGULAMA
}

$\ddot{O}_{z}$

Zeynep KARACA*

Türkiye'de 81 ilin patent sayısını etkileyen faktörlerin araştırıldığ bu çalışmada bağımlı değişken patentin olup olmaması iken; bağımsız değişkenler kişsi başı gayrisafi yurtiçi hâslla, lisansüstü mezun saylsl, teknoloji gelişstirme bölgeleri ve devlet ve vakıf üniversitelerinin toplamindan oluşan üniversite saylsıdır. Model tahmininde logit model tercih edilmiş olup tüm veriler 2018 yllına aittir. Model tahmin sonuçlarına göre ildeki patent üzerinde kişi başı gayrisafi yurtiçi hâsıla, lisansüstü mezun sayısı ve teknoloji geliştirme bölgeleri pozitif bir etkiye sahipken üniversite saylsı negatif bir etkiye sahiptir.

Anahtar Kelimeler: Patent, Logit Model, Yenilik, Şehir.

\section{AN APPLICATION ON FACTORS AFFECTING THE PATENT NUMBER OF PROVINCES}

\begin{abstract}
In this study, in which the factors affecting the number of patents in 81 provinces are investigated, the dependent variable is whether there is a patent; independent variables are gross domestic product per capita, number of graduate graduates, technology development regions, and the number of universities consisting of state and foundation universities. Logit model was preferred in model estimation and all data belong to 2018. According to the model estimation results, the per capita gross domestic product, the number of graduate graduates and technology development regions have a positive effect on the patent in the province, while the number of universities has a negative effect.
\end{abstract}

Keywords: Patent, Logit Model, Innovation, Province.

\section{GíRiș}

Ekonomik büyümenin kaynakları, teknolojik değişim oranı, farklı firma ve ülkelerin rekabetçi konumu, alternatif endüstriyel yapıların ve düzenlemelerin dinamizmi hakkındaki soruların hepsi farklı yenilik kavramları etrafında dönme

Bu makale için önerilen kaynak gösterimi (APA 6. Sürüm):

Karaca, Z. (2021). İllerin patent sayısını etkileyen faktörler üzerine bir uygulama. Dokuz Eylül Üniversitesi Sosyal Bilimler Enstitüsü Dergisi, 23 (3), 1179-1192.

* Dr. Öğr. Üyesi, Erzurum Teknik Üniversitesi, İktisadi ve İdari Bilimler Fakültesi, İktisat Bölümü, ORCID: 0000-0001-8046-7222, zeynep.karaca@erzurum.edu.tr. 
eğilimindedir (Griliches, 1990, s. 1661). Yenilik toplam faktör verimliliğini artırdığından ve firmaların etkili ve çevre dostu bir yöntemle düşük maliyetle daha çok çıktı elde etmelerini sağladığından çok önemlidir. Yenilik ayrıca yeni büyüme motorlarını farklı endüstrilere getirir ve böylece çoğu gelişmiş ekonomide talebi artırır (Im ve Shon, 2019, s. 1). Bilgi düzeyindeki ilerlemeler, tarihsel olarak da ekonomik gelişmeyi büyük oranda etkilemiştir. Yeniliğe götüren ekonomik açıdan yararlı yeni bilgiler ekonomik büyümede, uluslararası ticarette ve bölgesel kalkınmada önemli bir rol oynamaktadır. Bilginin ve dolayısıyla yeniliğin ekonomide oynadığ rolü tam olarak anlamak için bilgi girdilerinin ve bilgi çıktılarının ölçülmesi kritiktir. Genellikle yenilik sürecinde girdi olarak Ar-Ge harcamaları, çıktı olarak ise patentlenen icatlar kullanılır (Acs vd., 2002, s. 1069). İşletmeler ve kamu kurumları tarafindan yenilikleri korumak için patentlerin kullanımı yenilik sürecinin gelişimiyle yakından ilgilidir. Yenilik, teknik bir probleme yeni bir çözümdür ve patentlerle korunabilir. Patentler, bir buluş sahibinin buluşlarının ticari kullanımını kontrol edebilmesini sağlayarak, teknolojileri çığır açan ve ticari olarak başarılı olan mucitlerin çıkarlarını korur. Ticari olarak başarılı patent korumalı teknolojilerden elde edilen gelirler, daha fazla teknolojik araştırma ve geliştirmeyi (Ar-Ge) finanse etmeyi mümkün kılar ve böylece gelecekte daha da fazla yeniliğin yapılabilir olma şansını artırır (World Intellectual Property Organization).

Firmaların rekabet gücü, yenilik oluşturma becerileriyle ve bu becerileri destekleyen Ar-Ge çalışmalarıyla, kullandıkları teknolojilerle, yatırım kapasiteleriyle yakından ilgilidir (Işık ve Keskin, 2013, s. 42). Yenilik bir firma için önemli bir rekabet avantajı olduğundan onu rakipleri tarafından taklit edilmekten koruma mekanizması bir firmanın yenilik yapma motivasyonu için çok önemlidir (Im ve Shon, 2019, s. 2). Söz konusu korumayı sağlamak için verilen patent bir buluşun kullanımındaki mülkiyet hakkı olduğundan (Jaffe vd., 1993, s. 580) yetkili bir devlet kurumu tarafindan verilen ve belirli bir yıl boyunca yeni bir cihaz veya işlemin üretiminden veya kullanımından başkasını dışlama hakkını veren bir belgedir. Patent üzerindeki hak, buluş sahibi tarafından bir başkasına (işverenine, bir kuruma) devredilebilir, satılabilir veya kullanımı için lisans verilebilir. Bir kimyasal formül, mekanik bir cihaz veya bir işlem (prosedür) ve hatta bir bilgisayar programı icad1 için patentler verilebilir (Griliches, 1990, ss. 1662- 1666). Patentin verilebilmesi için buluşun basit ve önemsiz olmaması, çözümünün zor olması yani ilgili teknolojinin yetenekli uygulayıcılar tarafından açık görünmemesi, faydalı olması yani potansiyel ticari değere sahip olması gerekir. Eğer patent verilirse buluşun öncülleri hakkında kapsamlı bilgiler içeren kamuya ait bir belge oluşturulur. $\mathrm{Bu}$ bilgiler arasında referanslar veya alıntılar da vardır. Alıntılar, patentin taşıdığ 1 mülkiyet hakkının kapsamını sınırlandıran hukuki işlev görür. Patentin verilmesi patentte yer alan fikrin alıntılarla temsil edildiği şekliyle önceki bilgi durumuna göre yeni ve faydalı bir katkıyı temsil ettiğine dair yasal bir beyandır. Bu nedenle, patent $X^{\prime}$ 'in patent $Y$ tarafından alıntılanması $X$ 'in Y'nin üzerine inşa ettiği önceden var olan bir bilgi parçasını temsil ettiği anlamına gelir (Jaffe vd., 1993, s. 580). 
Firmalar Ar-Ge çalışmaları yaparak yeni bir ürün ve yeni bir üretim süreci ortaya koyarlar. Bu Ar-Ge çalışmalarının sonuçlarının firma veya ülkeler üzerindeki en büyük göstergesi patenttir (Yaylalı vd., 2010, s. 14). Patent sisteminin amac1, hem buluş sahibi için geçici bir tekel sağlamak hem de bu icadın üretimi veya yeni sürecin işleyişi için gerekli bilgilerin erken açıklanmasını zorlayarak buluşu ve teknik ilerlemeyi teşvik etmektir (Griliches, 1990, s. 1663). Patent yasası buluşa, mülkiyet haklarını ekleyerek yeniliği teşvik etmek, yeniliğin başkaları tarafından kullanılmasını önlemek böylece yenilikçinin yatırım maliyetlerini telafi etmesine izin vermektedir (Bergin, 2018, ss. 439-440).

Patentler mucitleri hakkında ayrıntılı coğrafi bilgiler içerdiğinden bu izlerin gerçekte nereye gittiği incelenebilir (Jaffe vd., 1993, s. 578). Patent sahipleri tek başlarına çalışmazlar; yeni fikirlerin yaratılması çoğu kez farklı bireylerden, yerlerden, kurumlardan ve kuruluşlardan gelen mevcut bilgilerin bütünleştirilmesini ve yeniden birleştirilmesini içeren bir süreçtir. Kent merkezlerinin boyutu ve yoğunluğu kişiler arası etkileşimleri teşvik eder ve böylece gelişmiş bilgi akışları için daha büyük firsatlar yaratır. Sonuç olarak, tarihsel olarak da şehirler pek çok yeniliğin meydana geldiği yerler olmuştur. Şehirlerin bilim ve teknolojinin gelişiminde ve yeniliklerin ortaya çıkmasında oynadığı ayrıcalıklı rol, tarihçiler, şehirciler, antropologlar ve bölgesel ekonomistler tarafından belgelenmiştir. Yakın zamanlarda şehirlerin, beşeri sermayenin entegrasyonu ve yeniliklerin kuluçka merkezi olarak oynadığı rol, bireyler ve firmalar arasındaki bilgi yayılmasının büyüme için gerekli temeller olduğunu öne süren yeni ekonomik büyüme teorisi tarafindan yeniden keşfedilmiştir. Büyümenin fikirlerin akışına ve değiş tokuşuna bağlı olduğu fikri doğal olarak şehirlerin ekonomik ve sosyal rollerinin tanınmasına yol açar. Üstelik bu süreç kendi kendini pekiştirir. Şehirlerde bilginin yayılması ve yoğunlaşması eğitimli, yüksek vasıflı, girişimci ve yaratıcı bireylerin şehirlerde ikamet ederek daha fazla bilginin yayılmasına ve çekilmesine katkıda bulunur. Büyük şehirlerdeki daha yüksek birey ve firma yoğunlaşmalarının fikirlerin yaratılmasını kolaylaştırması beklenir. $\mathrm{Bu}$ ortam sonuçta yaratıcı bireyleri ve firmaları buraya çeker ve böylece yenilik döngüsünü sürdürür (Bettencourt vd., 2007, ss. 107-108).

Şehirlerin bilim ve teknolojide oynadıkları bu roller dikkate alınarak bu çalışmada da il düzeyinde patent sayısını etkileyen faktörler logit model kullanılarak analiz edilmek istenmiştir. Çalışmanın ilk bölümünde patent sayısını etkileyen faktörler üzerine literatürde yer alan çalışmalara yer verilecektir. Sonraki bölümde model tahmininde kullanılan veriler ve yöntem tanıtılacaktır. Model tahminin ardından elde edilen sonuçlar ampirik bulgular başlığı altında tartışılacak ve son olarak sonuç bölümünde önerilere yer verilecektir. 


\section{LITERATÜR ÖZETI}

Patentleri yenilik yapmanın çıktısı olarak kullanan çalışmalara literatürde rastlanmaktadır (Schwartz vd., 2012; Block ve Spiegel, 2013; Xu vd. 2014; Hayward vd. 2017; Zhang vd. 2017; Janger vd. 2017; Gachanja vd. 2020; Taalbi 2020). Patentleri yeniliğin çıktısı olarak kabul eden çalışmaları ülke bazında yapılan çalışmalar ve firma bazında yapılan çalışmalar olarak sınıflandırmak mümkündür.

Ülkeler için yapılmış olan çalışmalardan; Tunç (2008), Türkiye'nin patent performansını araştırdığı çalışmasında, üniversite sanayi işbirliğinin olmaması ve teknolojik taklitçilikten dolayı bu performansın kötü olduğunu belirtmiştir. Stern vd. (2000), 17 OECD ülkesinin 1973-1996 yılları verilerini kullanarak patent kararlarını incelemişlerdir. Bağımlı değişken patent sayısı iken bağımsız değişkenler gayrisafi yurtiçi hâsıla, kamu ve özel Ar-Ge harcamalarıdır. Patent sayısının bu değişkenlerle birlikte arttığı ve eğitim harcamalarının da ayrıca patent sayısını artırdığı ortaya konulmuştur. Tüylüoğlu ve Saraç (2012), gelişmiş ve gelişmekte olan ülkelerin inovasyon bakımından farklı olduğunu iddia ettikleri çalışmalarında, 26 gelişmiş ve 18 gelişmekte olan ülkeye ait 1998-2007 verilerini kullanarak dinamik en küçük kareler yöntemi tahmin etmişlerdir. Çalışmada bağımlı değişken patent sayısı iken; bağımsız değişkenler gayrisafi yurtiçi hâsıla, Ar-Ge harcamaları, beşeri sermaye, doğrudan yabancı yatırımlar, dışa açıklık, fikri mülkiyet haklarıdır. Model tahmin sonucuna göre gayrisafi yurtiçi hâsıla, doğrudan yabancı yatırımlar, dışa açıklık ve fikri mülkiyet hakları hem gelişmiş hem de gelişmekte olan ülkelerde patent sayısı üzerinde anlamlı bir etkiye sahiptir. Canh vd. (2019), panel veri kullanarak kurumsal kalite, dışa açıklık ve doğrudan yabancı yatırım akışlarının 1996-2014 yılları arasında 84 ülkenin inovasyon çıktısı üzerindeki etkisini araştırmışlardır. İnovasyon çıktısını temsil etmek için patent sayısı seçilmiştir. Model sonuçlarına göre kurumsal kalite, içe doğru olan doğrudan yabancı yatırım akışı patenti pozitif etkilerken dışa açıklık negatif etkilemektedir.

Firmalar için yapılmış olan çalışmalardan olan; Chan (2010), Avustralya, Brezilya, Kanada, Çin, Japonya ve Güney Afrika'da 9 tarımsal biyoteknoloji firmasının 1990-2000 yıllarında patent başvuru kararlarını araştırmıştır. Bağımlı değişken "patent başvurusu yapılıysa 1, yapılmadıysa 0" şeklinde tanımlanmıştır. Bağımsız değişkenler ise ihracat, ithalat ve üretimdir. Üretim dışındaki değişkenlerin patent başvurusu üzerinde anlamlı etkisi olduğu tespit edilmiş̧ir. Beneito vd. (2018), 2005-2013 yıllarında 10'dan fazla çalışanı olan İspanyol imalat sanayi ve hizmetler sektörü firmalarının patent başvuru kararlarını analiz etmişlerdir. Çok değişkenli panel probit model kullanılarak yapılan tahminde bağımlı değişken firmanın patent başvurusu yapıp yapmadı̆̆ yoğunluğu, Ar-Ge harcamaları, doktoralı işgücü, gölge değişken olarak ihracat (Avrupa Birliği'ne ihracat yapıldıysa 1, Avrupa Birliği dışına yapıldıysa 0)tır. Sonuçlara göre patent başvuruları firmaların Avrupa Birliği'ne yaptıkları ihracat ve Ar-Ge biriminde çalışan doktoralı işgücü ile pozitif ilişkilidir. Chen ve Zhang (2019), Çin'de son zamanlarda patent sayısında meydana gelen artışı dikkat çekici 
bulduklarından Çin firmaları tarafından yapılan patent başvurularındaki artışın itici güçlerini incelemişlerdir. Ulaştıkları sonuçlara göre Ar-Ge yatırımının her tür patentleme faaliyeti üzerinde olumlu ve önemli bir etkisi vardır. Doğrudan yabancı yatırımların patent başvuruları üzerindeki uyarıcı etkisi yalnızca faydalı model patentleri ve tasarım patentleri için güçlüdür. Patent sübvansiyonlarının ise sadece tasarım patentleri üzerinde olumlu etkisi vardır. Yaşar (2020), Ar-Ge'de üniversite sanayi işbirliğinin patent başvurularına etkisini araştırdığ bakımından üniversite sanayi işbirliğinin üst düzeyde olmasının patentlenebilir ürün ve hizmetleri artıran en önemli faktörlerden biri olduğu sonucuna ulaşmıştır. Chen vd. (2021); Ren vd. (2021); Zhang vd. (2021) firma ve patent performansını araştıran diğer çalışmalardan bazılarıdır.

Yukarıdaki literatür taramasından görüldüğü gibi patenti etkileyen faktörler olarak genellikle makro değişkenler seçilmiştir ve patent durumu ülke veya firma bazında incelenmiştir. Bu çalışmada mikro veriler kullanılarak il düzeyinde patenti etkileyen faktörler tespit edilmeye çalışılacaktır.

\section{VERİ SETİ VE YÖNTEM}

81 ilde tescil edilmiş patentin varlığını etkileyen faktörlerin araştırıldığ bu çalışmada kişi başı gayrisafi yurtiçi hâsıla (GSYH), yüksek lisans ve doktora mezunu sayısı, teknoloji geliştirme bölgeleri sayısı ve devlet ve vakıf üniversiteleri toplam sayısının illerin tescil edilen patent sayıları üzerindeki etkisi araştırılmıştır. Çalışmada kullanılan verilerin nasıl kullanıldığı ve nereden temin edildiği Tablo 1 'de sunulmuştur.

Tablo 1: Veriler ve Kaynakları

\begin{tabular}{|l|l|}
\hline Veriler & Kaynağı \\
\hline $\begin{array}{l}\text { İlde tescil edilmiş patent olup olmadığı } \\
\text { (bağımlı değişken; yapay değişken olarak } \\
\text { ifade edilmiştir) }\end{array}$ & Türk Patent ve Marka Kurumu \\
\hline İl kişi başı GSYH (bağımsız değişken) & Türkiye İstatistik Kurumu \\
\hline $\begin{array}{l}\text { İldeki lisansüstü mezun sayısı (bağımsız } \\
\text { değişken) }\end{array}$ & Türkiye İstatistik Kurumu \\
\hline $\begin{array}{l}\text { İldeki devlet ve vakıf üniversiteleri sayısı } \\
\text { (bağımsız değişken) }\end{array}$ & Öğrenci Seçme ve Yerleştirme Merkezi (ÖSYM) \\
\hline $\begin{array}{l}\text { İldeki teknoloji geliştirme bölgeleri sayısı } \\
\text { (bağımsı değişken) }\end{array}$ & Sanayi ve Teknoloji Bakanlığı \\
\hline
\end{tabular}

Devlet ve vakıf üniversiteleri toplamından oluşan üniversite sayısı ÖSYM tarafından yayımlanan tercih kılavuzundan elde edilmiştir. İl bazında kişi başı GSYH verisi en son 2018 yılında yayımlandığından Tablo 1'de yer alan veriler 81 ile ait 2018 yılı verileridir. Çalışmada söz konusu veri seti kullanılarak Eviews paket 
programı yardımıyla analizler yapılmıştır. Analizler maksimum olabilirlik yöntemi ile tahmin edilen ikili lojistik regresyon modeline dayanmaktadır.

\section{Logit Model}

\section{Modelin yapısı}

Bağımlı değişkenin iki durumlu olduğu modellere ikili tercih modelleri denir. Bağımlı değişkenin ikiden fazla değer aldığı modeller de çoklu tercih modelleri olarak adlandırılır. Her iki modelde de temel amaç tercih olasılığının belirlenmesidir. Bağımlı değişkenin iki durumlu olduğu modeller doğrusal olasılık modeli, logit model ve probit modelidir (Tar1, 2011, s.245).

Doğrusal olasılık modeli bir karar biriminin belli bir tercihini yapma olasılığının onun sahip olduğu özelliklerinin doğrusal bir fonksiyonu olduğunu varsayar ve basitçe eşitlik (1) gibi oluşturulur.

$$
Y_{i}=\beta_{0}+\beta_{1} X_{i}+u_{i}
$$

Burada $X_{i}$ veri iken $Y_{i}$ nin koşullu beklenen değeri $E\left(Y_{i} \mid X_{i}\right), X_{i}$ veri iken olayın gerçekleşmesinin koşullu olasıllığ $1\left[\mathrm{P}\left(\mathrm{Y}_{\mathrm{i}}=1 \mathrm{IX}_{\mathrm{i}}\right)\right]$ olarak yorumlanabilir (Özer, 2004: 62). Doğrusal olasılık modeline ilişkin bazı eleştiriler vardır. Bunlar:

Hata teriminin normal dağılımlı olmaması

- $\quad$ Hata teriminin değişen varyanslı olması

gösteren bir ölçü olamaması

$\mathrm{R}^{2}$ değerinin genellikle küçük çıkarak, ilişkinin uyumunu

şeklinde sıralanmaktadır (Tarı, 2011, s. 249).

Olasılı̆̆ın 0-1 aralığında kalmasını sağlayan ve katsayılar itibariyle doğrusal olmayan probit modeli, genellikle gözlenemeyen bir fayda indeksi dikkate alınarak oluşturulmaktadır (Özer, 2004: 70). Probit modelinin tahmini için en küçük kareler yöntemi uygun değildir. En çok benzerlik yöntemi ile probit modelinin parametrelerinin tutarlı tahminlerini elde etmek mümkündür. Ancak, anlaşılması ve yorumlanması bakımından karmaşık olan bu model, logit modeli kadar yaygın bir şekilde kullanılmamaktadır (Tar1, 2011, s. 253).

Doğrusal olasılık modelinde karşılaşılan sorunları gidermek için normal birikimli dağılım fonksiyonuna dayalı olarak türetilen probit modeline alternatif olarak oluşturulan bir başka tercih modeli logit modelidir. Bu model oluşturulurken izlenen süreç, probit modelde izlenen sürecin aynısıdır. Aralarındaki tek fark dayandıkları birikimli dağılım fonksiyonudur. Normal birikimli dağılım fonksiyonundan türetilen probit modelinin aksine, logit model lojistik birikimli dağlım fonksiyonundan türetilmektedir (Özer, 2004, s. 75).

Logit model eşitlik (2)'de gösterilen lojistik birikimli dă̆ı̆lım fonksiyonundan türetilmektedir. 


$$
P_{i}=\frac{1}{1+e^{-I}}=\frac{1}{1+e^{-\left(\beta_{0}+\beta_{1} X_{i}\right)}}
$$

Burada;

$\mathrm{I}_{\mathrm{i}}=\mathrm{iki}$ sonuçlu bağımlı değişken

$\mathrm{P}=$ incelenen olayın gerçekleşme olasılığg1

$\mathrm{e}=$ hata terimi

$\mathrm{X}_{\mathrm{i}}=$ bağımsız değişkenler

$\beta_{0}, \beta_{1}=$ katsayılardır.

$\mathrm{I}_{\mathrm{i}}-\infty$ ile $+\infty$ arasında değer alırken, $\mathrm{P}_{\mathrm{i}}$ 0-1 arasında değer alır, ayrıca $\mathrm{P}_{\mathrm{i}}$ ile $\mathrm{I}_{\mathrm{i}}$ arasında doğrusal olmayan bir ilişki bulunmaktadır.

Bağımsız değişken $\mathrm{k}$ adet olduğunda logit model

$$
l_{i}=\ln \left(\frac{P_{i}}{1-P_{i}}\right)=\beta_{0}+\beta_{1} X_{1}+\beta_{2} X_{2}+\cdots+\beta_{k} X_{k}+u_{i}
$$

şeklinde ifade edilir.

Logit modelde katsayılar doğrudan bağımsız değişkenin olasılık üzerindeki etkisini vermemektedir. Olasılığın bağımsız değişkene göre değişme oranı sadece ilgili katsayıya ( $\beta$ ) değil, aynı zamanda değişimin ölçüldüğü olasılığın düzeyine de bağlıdır (Özer, 2004, s.77). Yani,

$$
\frac{d P_{i}}{d X_{i}}=P_{i}\left(1-P_{i}\right) \beta_{i}
$$

dir. $\mathrm{Bu}$ denklem, bağımsız değişkenlerdeki bir değişimin olayın gerçekleşme olasılığı üzerindeki değişimini verecektir. Logit modelde sabit terim bağımsız değişkenler sıfır olduğunda olayın gerçekleşme log-olasılık oranının değerini verirken, eğim katsayıları bağımsız değişkenlerdeki 1 birimlik değişmeye karşılık olayın gerçekleşme olasılığındaki değişmeyi ölçmektedir (Gujarati, 1999, p.555).

\section{AMPÍRIK BULGULAR}

Logit model tahmin sonuçlarına geçmeden önce çalışmada kullanılan verilere ait tanımlayıcı istatistikler Tablo 2'de gösterilmektedir.

Tablo 2: Tanımlayıcı İstatistikler

\begin{tabular}{|l|l|l|l|l|l|}
\hline & Patent & $\begin{array}{l}\text { Kişi başı } \\
\text { GSYH }\end{array}$ & $\begin{array}{l}\text { Lisansüstü } \\
\text { mezunu }\end{array}$ & $\begin{array}{l}\text { Teknoloji } \\
\text { geliştirme } \\
\text { bölgeleri }\end{array}$ & $\begin{array}{l}\text { Üniversite } \\
\text { sayisı }\end{array}$ \\
\hline Ortalama & 0.862500 & 34239.81 & 14636.06 & 1.037500 & 2.387500 \\
\hline Medyan & 1.000000 & 31742.00 & 4446.000 & 1.000000 & 1.000000 \\
\hline
\end{tabular}




\begin{tabular}{|c|c|c|c|c|c|}
\hline Maksimum & 1.000000 & 79254.00 & 343921.0 & 10.00000 & 53.00000 \\
\hline Minimum & 0.000000 & 15121.00 & 866.0000 & 0.000000 & 1.000000 \\
\hline $\begin{array}{ll} & \text { Standart } \\
\text { Sapma } & \end{array}$ & 0.346547 & 12209.12 & 43020.28 & 1.664550 & 6.165428 \\
\hline
\end{tabular}

Tablo 2'de görüldüğü gibi patent verisi yapay değişken olarak ifade edildiğinde 0-1 değerleri alan kesikli gölge değişken iken, diğer değişkenler sürekli değişkenlerdir. Bağımlı değişken aşağıdaki şekilde ifade edilmiştir.

2018 yılında söz konusu ilin tescil edilmiş patenti varsa $=1$

2018 yılında söz konusu ilin tescil edilmiş patenti yoksa $=0$

Yine tanımlayıcı istatistiklere göre 81 ilde kişi başı GSYH ortalama olarak 34239.81; yüksek lisans ve doktora mezunları toplamından oluşan lisansüstü mezun sayısı ortalama olarak 14636.06; illerdeki teknoloji geliştirme bölgelerinin sayısı ortalama olarak $1 \mathrm{iken}$ devlet ve vakıf üniversiteleri toplamından oluşan üniversiteyi sayıs1 ise ortalama olarak 2'dir.

\section{Logit Model Tahmin Sonuçları}

Çalışmanın bu kısmında Eviews paket programı yardımıyla tahmin edilen illerin tescil edilmiş patent sayısını etkileyen faktörler logit model yardımıyla araştırılmıştır. Model tahmin sonuçları Tablo 3 'te sunulmuştur.

Tablo 3: Logit Model Tahmin Sonuçları

\begin{tabular}{|l|l|l|l|l|}
\hline Değişkenler & Katsayı & Standart Hata & $\mathbf{Z}$ istatistik & Prob. \\
\hline $\begin{array}{l}\text { Kişi başı } \\
\text { GSYH }\end{array}$ & 0.000177 & $7.87 \mathrm{E}-05$ & 2.243154 & $0.0249^{* *}$ \\
\hline $\begin{array}{l}\text { Lisansüstü } \\
\text { mezun }\end{array}$ & 0.001997 & 0.000513 & 3.893179 & $0.0001^{*}$ \\
\hline $\begin{array}{l}\text { Teknoloji } \\
\text { geliştirme } \\
\text { bölgesi }\end{array}$ & 2.814498 & 1.628682 & 1.728083 & $0.0840^{* * *}$ \\
\hline $\begin{array}{l}\text { Üniversite } \\
\text { sayısı }\end{array}$ & -2.450214 & 0.904583 & -2.708666 & $0.0068^{*}$ \\
\hline $\begin{array}{l}\text { Sabit Terim } \\
\text { Log- } \\
\text { olabilirlik }\end{array}$ & -6.145413 & 2.538757 & -2.420639 & $0.0155^{* *}$ \\
\hline $\begin{array}{l}\text { Ortalama } \\
\text { log- } \\
\text { olabilirlik }\end{array}$ & -9.257503 & & \\
\hline $\begin{array}{l}\text { Kıstllı log- } \\
\text { olabilirlik }\end{array}$ & -0.115719 & & \\
\hline $\begin{array}{l}\text { LR } \\
\text { istatistiği }\end{array}$ & 45.54886 & & \\
\hline
\end{tabular}




\begin{tabular}{|l|l|}
\hline Prob. LR & 0.000000 \\
\hline $\begin{array}{l}\text { McFadden } \\
\mathrm{R}^{2}\end{array}$ & 0.710991 \\
\hline $\begin{array}{l}\text { Akaike } \\
\text { bilggi kriteri }\end{array}$ & 0.356438 \\
\hline $\begin{array}{l}\text { Schwarz } \\
\text { bilgi kriteri }\end{array}$ & 0.505314 \\
\hline $\begin{array}{l}\text { Hannan- } \\
\text { Quinn } \\
\text { kriteri }\end{array}$ & 0.416126 \\
\hline
\end{tabular}

Not: *\%1 önem düzeyinde, $* * \% 5$ önem düzeyinde, $* * * \% 10$ önem düzeyinde anlamlılığı göstermektedir.

Tablo 3'te görüldüğü gibi, lisansüstü mezun sayıs1 ve üniversite sayıs1 değişkenleri \%1 önem düzeyinde; kişi başı GSYH değişkeni \%5 önem düzeyinde ve teknoloji geliştirme bölgesi sayısı değişkeni \%10 önem düzeyinde anlamlıdır. Olabilirlik oranı test istatistiğine ait prob. Değeri modeldeki tüm katsayıların $\% 5$ önem düzeyinde istatistiki bakımdan anlamlı olduğunu göstermektedir $(0.00000<0.01)$. Ayrıca uyumun iyiliğini gösteren McFadden $\mathrm{R}^{2}$ değeri \%71.0991 olarak bulunmuştur.

Modeldeki sabit terim, bağımsız değişkenlerin sıfır olması halinde illerin tescil edilmiş patentlerinin olmasının log-olasılık oranını verir. Katsayıların işaretleri ise bağımlı ve bağımsız değişkenler arasındaki ilişkinin yönünü verir. Buna göre kişi başı GSYH, lisansüstü mezun sayısı ve teknoloji geliştirme bölgesi sayısı illerin tescil edilmiş patentlerinin olma olasılığını pozitif etkilerken; üniversite sayısı negatif etkilemektedir. Eğim katsayılarının büyüklüğü de bağımsız değişkenlerde meydana gelecek 1 birimlik bir değişmenin illerin tescil edilmiş patentlerinin olma olasıllğı üzerindeki etkisini göstermektedir. Buna göre lisansüstü mezun sayısı, teknoloji geliştirme bölgeleri sayısı ve üniversite sayısı sabitken kişi başı GSYH'da meydana gelecek 1 birimlik artı̧s illerin tescil edilmiş patentlerinin olmasının logolasılık oranını 0.000177 artıracaktır. Kişi başı GSYH, teknoloji geliştirme bölgesi sayısı ve üniversite sayısı sabitken lisansüstü mezunları sayısının 1 kişi artması illerin tescil edilmiş patentlerinin olmasının log-olasılık oranını 0.001997 artıracaktır. Kişi başı GSYH, lisanüstü mezun sayısı ve üniversite sayısı sabitken yeni bir teknoloji geliştirme bölgesinin kurulması illerin tescil edilmiş patentlerinin olmasının log-olasılık oranını 2.814498 artıracaktır. Kişi başı GSYH, lisansüstü mezun sayısı ve teknoloji geliştirme bölgesi sayısı sabitken yeni bir üniversite kurulması illerin tescil edilmiş patentlerinin olmasının log-olasılık oranını 2.450214 azaltacaktır.

Logit model çerçevesinde yapılabilecek bir diğer yorum da bağımsız değişkenlerin belirli değerleri için olayın kendi olasılığını tahmin etmektir. Bu olasılığı tahmin etmek için eşitlik (2) çözülmelidir. Bağımsız değişkenlerin örneklem 
değerleri olarak kişi başı GSYH 15121 TL; lisansüstü mezun sayısı olarak 866; teknoloji geliştirme bölgesi sayısı olarak 1 ve üniversite sayısı olarak 2 seçilmiştir.

$$
\begin{gathered}
P_{i}=\frac{1}{1+e^{-I_{i}}}= \\
\frac{1}{1+e^{-[-6.145413+0.000177(15121)+0.001997(866)+2.8144988(1)-2.450214(1)}}=0.20
\end{gathered}
$$

Bu sonuca göre kişi başı GSYH'sı 15121 TL olan, lisansüstü mezun sayısı 866 kişi olan, 1 adet teknoloji geliştirme bölgesi ve 1 adet üniversitesi olan bir ilin tescil edilmiş patentinin olma olasılı $\mathrm{g} 1 \% 20$ 'dir.

Logit modelde katsayılar doğrudan bağımsız değişkenlerdeki bir değişimin bağımlı değişkenin beklenen değeri üzerindeki etkisi olarak yorumlanamamaktadır. Logit modelde katsayı yorumlarının yapılabilmesi için marjinal etkiler hesaplanır. Olasılığın bağımsız değişkene göre değişme oranı sadece ilgili katsayıya değil, aynı zamanda değişimin ölçüldüğü olasılığın düzeyine de bağlıdır (Özer, 2004: 198). Bağımsız değişkenlerdeki bir değişimin illerin tescil edilen patent sayısının olma olasıllı̆ı üzerinde meydana getireceği değişim belirlenmektedir. Buna göre marjinal etkiler aşağıdaki eşitliklerle hesaplanmıştır.

$$
\begin{gathered}
\frac{\partial P}{\text { dkişibaşıGSYH }}=P(1-P) \beta_{1}=0.20(1-0.20)(0.000177) \\
=0.00002832 \quad(6) \\
\frac{\partial P \quad=0.00031952 \quad(7)}{\text { dlisansüstümezun }}=P(1-P) \beta_{2}=0.20(1-0.20)(0.001997) \\
\frac{\partial P \quad(8)}{\partial \text { teknolojiggeliştirmebölgeleri }}=P(1-P) \beta_{3}=0.20(1-0.20)(2.814498) \\
=0.45031968 \quad(8) \\
\frac{\partial P \quad}{\text { düniversite }}=P(1-P) \beta_{4}=0.20(1-0.20)(-2.450214) \\
=-0.39203424 \quad \text { (9) }
\end{gathered}
$$

\section{TARTIŞMA}

Çalışmada 81 ilin tescil edilen patent sayısını etkileyen faktörler uygulamada en sik kullanılan ikili tercih modellerinden olan logit model ile tahmin edilmiştir. Literatürde patenti etkileyen faktörler olarak daha çok eğitim, Ar-Ge harcamaları ve üniversite sanayi iş birliği üzerinde durulmuş ve genellikle ülke statüsünde bu durum ele alınmıştır. Bu çalışmada il bazında patentlerin durumu ele alınarak literatüre farklı bir bakış açısı katmak amaçlanmıştır.

İl bazında kişi başına GSYH verisi en son 2018 yılında yayımlandığından çalışmadaki tüm veriler 2018 yılına aittir. Modelde bağımlı değişken yapay değişken olarak tanımlanmıştır. 2018 yılında söz konusu ilin tescil edilmiş patenti varsa 1, 
yoksa 0 olarak kodlanmıştır. Bağımsız değişkenler ise kişi başı GSYH, lisansüstü mezun sayısı, teknoloji geliştirme bölgesi sayısı ve devlet ve vakıf üniversitelerinin toplamından oluşan üniversite sayısıdır.

Model tahmin sonuçlarına göre tüm bağımsız değişkenler istatistiki olarak anlamlı bulunmuştur. Katsayıların işaretlerine bakıldığında kişi başı GSYH, lisansüstü mezun sayısı ve teknoloji geliştirme bölgeleri patenti pozitif etkilerken üniversite sayısı negatif etkilemektedir. Logit modelde katsayılar doğrudan bağımsız değişkenlerdeki bir değişimin bağımlı değişkenin beklenen değeri üzerindeki etkisi olarak yorumlanamadığından modelde katsayı yorumlarının yapılabilmesi için marjinal etkiler hesaplanır. Marjinal etkiler ile bağımsız değişkenlerdeki bir değişimin illerin tescil edilen patent sayısının olma olasılığı üzerinde meydana getireceği değişim belirlenmektedir. Buna göre, 81 ilde tescil edilen patentin olma olasılığ 1 ; kişi başı GSYH 1 birim arttığında 0.00002832 artacaktır, lisansüstü mezun sayısı 1 kişi arttığında 0.00031952 artacaktır, yeni bir teknoloji geliştirme bölgesi kurulduğunda 0.45031968 artacaktır ve yeni bir üniversite kurulduğunda 0.39203424 azalacaktır.

Ar-Ge harcamaları patentin en büyük yansımasıdır, fakat il düzeyinde ArGe harcamaları yayımlanmadığından analize dahil edilememiştir ve bu durum çalışmanın kısıtını oluşturmaktadır.

\section{SONUÇ}

Patent bir buluşun kullanımındaki mülkiyet hakkı olduğundan yetkili bir devlet kurumu tarafından verilen ve belirli bir yıl boyunca yeni bir cihaz veya işlemin üretiminden veya kullanımından başkasını dışlama hakkını veren bir belgedir. Buluşu kimin üretmesine, satmasına patent sahibi karar verir. Ayrıca patentin kullanım lisansı başkasına verilebilir. Herhangi bir buluşun patentlenebilmesi için o buluşun yeni olması yani patent başvurusunun yapıldığ 1 tarihten önce dünyanın herhangi bir yerinde hiçbir şekilde halka açıklanmaması gerekir. Aynı zamanda buluşun yaratıcı olması, hâlihazırda bilinenler ile karşılaştırıldığında konu hakkında iyi bilgi ve deneyime sahip biri için açı olmaması ve endüstriyel kullanıma uygun olması gerekmektedir.

Patentler ve onları koruma altına alan fikri mülkiyet hakları; yeniliğe ve ekonomik büyümeye neden oldukları için politika yapıcılar için önemli bir araçtır. $\mathrm{Bu}$ çalışmada da patentler ve kişi başı gayrisafi yurtiçi hasıla arasında anlamlı ve pozitif bir ilişki bulunmuştur. Bunun yanında ildeki yüksek lisans ve doktora mezunlarının artmasıyla ildeki patent sayısının artacağı tespit edilmiştir. Ancak ilde tescil edilmiş patent olma olasılığına en büyük katkıyı ildeki teknoloji geliştirme bölgeleri yapmaktadır. Dolayısıyla illerde bu merkezlerin sayılarının artması patent sayısını artırarak şehirlerin daha yenilikçi ve rekabetçi olmalarına yol açacaktır. İl düzeyinde Ar-Ge harcamaları yayımlandığı takdirde çalışma daha da genişletilip ArGe harcamalarının illerin yeniliği üzerindeki etkisi araştırılabilir. 


\section{KAYNAKÇA}

Acs, Z. J., Anselin, L. \& Varga, A. (2002). Patents and innovation counts as measures of regional production of new knowledge. Research Policy, 31, 10691085 .

Beneito, P., Rochina-Barrachina, M. E. \& Sanchis, A. (2018). International patenting decisions: empirical evidence with Spanis firms. Economia Politica, 35, 579-599.

Bergin, J. (2018). Patent policy, investment and social welfare. International Journal of Industrial Organization, 61, 439-458.

Bettencourt, L. M. A., Lobo, J. \& Strumsky, D. (2007). Invention in the city: increasing returns to patenting as a scaling function of metropolitan size. Research Policy, 36, 107-120.

Block, J. H. \& Spiegel, F. (2013). Family firm density and regional innovation output: an exploratory analysis. Journal of Family Business Strategy, 4, 270-280.

Canh, N. P., Schinckus, C. \& Thanh, S. D. (2019). Do economic openness and institutional quality influence patents? evidence from gmm systems estimates. International Economics, 157, 134-169.

Chan, H. P. (2010). The Determinants of international patenting for nine agricultural biotechnology firms. The Journal of Industrial Economics, 58(2), 247278.

Chen, Z. \& Zhang, J. (2019). Types of patents and driving forces behind the patent growth in China. Economic Modelling, 80, 294-302.

Chen, Z., Zhang, J. \& Zi, Y. (2021). A cost benefit analysis of R\&D and patents: firm-level evidence from China. European Economic Review, 133, 1-28.

Gachanja, I. M., Nga'nga', S. I. \& Kiganane, L. M. (2020). Influence of organization learning on innovation output in manufacturing firms in Kenya. International Journal of Innovation Studies, 4, 16-26.

Griliches, Z. (1990). Patent statistics as economic indicators: a survey. Journal of Economic Literature, 28(4), 1661-1707.

Gujarati, D. N. (1999). Temel ekonometri, (Çev. Ü. Şenesen ve G.G. Şenesen), Literatür Yayıncılık, İstanbul.

Hayward, M., Caldwell, A., Steen, J., Gow, D. \& Liesch, P. (2017). Entrepreneurs' capital budgeting orientations and innovation outputs: evidence from Australian biotechnology firms. Long Range Planning, 50, 121-133. 
Iş1k, C. \& Keskin, G. (2013). Bilgi ekonomilerinde rekabet üstünlüğü oluşturulması açısından inovasyonun önemi. Atatürk Üniversitesi İktisadi ve İdari Bilimler Dergisi, 27(1), 41-57.

Im, H. J. \& Shon, J. (2019). The effect of technological imitation on corporate innovation: evidence from US patent data. Research Policy, 48, 1-18.

Jaffe, A. B., Trajtenberg, M. \& Henderson, R. (1993). Geographic localization of knowledge spillovers as evidenced by patent citations. The Quarterly Journal of Economics, 108 (3), 577-598.

Janger, J., Schubert, T., Andries, P., Rammer, C. \& Hoskens, M. (2017). The EU 2020 innovation indicator: a step forward in measuring innovation outputs and outcomes?. Research Policy, 2017, 30-42.

Özer, H. (2004). Nitel değişsenli ekonometrik modeller teori ve bir uygulama. Nobel Yayın Dağıtım, 1. Basım, Ankara.

Ren, S., Cheng, Y., Hu, Y. \& Yin, C. (2021). Feeling right at home: hometown CEOs and firm innovation. Journal of Corporate Finance. 66, 1-26.

Schwartz, M., Peglow, F., Fritsch, M. \& Günther, J. (2012). What drives innovation output from subsidized R\&D cooperation?- project -level evidence from Germany. Technovation, 32, 58-369.

Stern, S., Porter, M. E. \& Furman, J. L. (2000). The determinants of national innovative capacity. NBER Working Paper Series, Working Paper No: 7876, Cambridge.

Taalbi, J. (2020). Evolution and structure of technological systems - an innovation output network. Research Policy, 49, 1-22.

Tar1, R. (2011). Ekonometri. Umuttepe Yayınları, 7. Bask1, Kocaeli.

Tunç, H. (2008). Bir yenilik göstergesi olarak patent ve türkiye patent performansı. (Yayımlanmamış Yüksek Lisans Tezi). Süleyman Demirel Üniversitesi Sosyal Bilimler Enstitüsü, Isparta.

Tüylüoğlu, Ş. \& Saraç, Ş. (2012). Gelişmiş ve gelişmekte olan ülkelerde inovasyonun belirleyicileri: ampirik bir analiz. Eskişehir Osmangazi Üniversitesi IIBF Dergisi, 7(1), 39-74.

Xu, S., Fenik, A. P. \& Shaner, M. B. (2014). Multilateral alliances and innovation output: the importance of equity and technological scope. Journal of Business Research, 67, 2403- 2410.

Yaşar, N. (2020). Ar-Ge'de üniversite sanayi işbirliğinin patent başvurularına etkisinin istatistik analizi. International Journal of Applied Economic and Finance Studies, 5(1), 28-40. 
Yaylal1, M., Akan, Y. \& Iş̧k, C. (2010). Türkiye'de Ar-Ge yatırım harcamaları ve ekonomik büyüme arasındaki eş-bütünleşme ve nedensellik ilişkisi: 1990-2009. Bilgi Ekonomisi ve Yönetimi Dergisi, 5(2), 13-26.

Zhang, G., Duan, H. \& Zhou, J. (2017). Network stability, connectivity and innovation output. Technological Forecasting\&Social Change, 114, 339-349.

Zhang, Q., Chen, J., Zhang, P. \& Liu, H. (2021). How does the business cycle affect firm innovation? Evidence from China's listed companies. Emerging Markets Finance and Trade, DOI: 10.1080/1540496X.2021.1877132.

\section{İnternet Kaynakları}

Öğrenci Seçme ve Yerleştirme Merkezi, www.osym.gov.tr, Erişim Tarihi: 30.08.2020 30.08.2020

Sanayi ve Teknoloji Bakanlığı, www.sanayi.gov.tr, Erişim Tarihi:

Türkiye İstatistik Kurumu, www.tuik.gov.tr, Erişim Tarihi: 30.08.2020 30.08 .2020

Türk Patent ve Marka Kurumu, www.turkpatent.gov.tr, Erişim Tarihi:

World Intellectual Property Organization, www.wipo.int, Erişim Tarihi: 30.08.2020 